\title{
Behavior Problems in New York City's Children After the September 11, 2001, Terrorist Attacks
}

\author{
Jennifer Stuber, $\mathrm{PhD}$, and \\ Sandro Galea, MD, DrPH \\ New York Academy of Medicine
Sharon Vandivere, MPP, and
Kristen Moore, $\mathrm{PhD}$
Child Trends

\author{
Betty Pfefferbaum, MD, JD \\ University of Oklahoma
}

Gerry Fairbrother, PhD

New York Academy of Medicine

\begin{abstract}
Children's behavior was assessed with 3 cross-sectional random-digit-dial telephone surveys conducted 11 months before, 4 months after, and 6 months after September 11, 2001. Parents reported fewer behavior problems in children 4 months after the attacks compared with the pre-September 11 baseline. However, 6 months after the attacks, parents' reporting of behavior problems was comparable to pre-September 11 levels. In the 1st few months after a disaster, the identification of children who need mental health treatment may be complicated by a dampened behavioral response or by a decreased sensitivity of parental assessment to behavioral problems.
\end{abstract}

Pervasive and broad exposure to the September 11, 2001, terrorist attacks on the World Trade Center has raised concern about the mental health and wellbeing of New York City's (NYC's) children. In Manhattan, $10 \%$ of children experienced the loss of a relative or friend of the family, $41 \%$ saw a parent crying about the attacks, and $26 \%$ watched TV for more than $4 \mathrm{hr}$ a day in the week following the attacks, when coverage of the attacks dominated the media (Stuber et al., 2002). A national study reporting on children's distress based on parental assess-

Jennifer Stuber, $\mathrm{PhD}$, and Gerry Fairbrother, $\mathrm{PhD}$, $\mathrm{Di}$ vision of Health and Science Policy, New York Academy of Medicine; Sandro Galea, MD, DrPH, Center for Urban Epidemiologic Studies, New York Academy of Medicine; Betty Pfefferbaum, MD, JD, Department of Psychiatry and Behavioral Sciences, Health Sciences Center, University of Oklahoma; Sharon Vandivere, MPP, and Kristen Moore, PhD, Child Trends, Washington, DC.

This research was funded by grants from the United Way of New York City and the New York Community Trust, the Commonwealth Fund, and the MetLife Foundation; National Institute on Drug Abuse Grant R01 DA14219-01S1; National Institute of Mental Health Grants R01 MH66081-010 and R01 MH MH66391-01; and a grant from the William T. Grant Foundation. We acknowledge the contributions of David Vlahov to the development of these studies.

For reprints and correspondence: Sandro Galea, MD, DrPH, Center for Urban Epidemiologic Studies, New York Academy of Medicine, 1216 Fifth Avenue, New York, NY 10029-5293. E-mail: sgalea@nyam.org ment found higher levels of distress in NYC children compared with levels of distress among children in the rest of the nation (Schlenger et al., 2002). Research on NYC's public school children found that, 6 months after September 11, the impact on children's mental health was substantial (Hoven, Mandell, \& Duarte, 2003).

Behavior problems as well as posttraumatic stress disorder (PTSD), anxiety, and depression have been documented in children after exposure to traumatic events (Bolton, O'Ryan, \& Udwin, 2000; Burke, Borus, \& Burns, 1982; Earls, Smith, Reich, \& Jung, 1988; Giaconia et al., 1995; Goenjian et al., 2001; Shaw, Applegate, \& Schorr, 1996; Shaw et al., 1995). Relatively little is known about the progression of psychological sequelae in populations of children after disasters (Bolton et al., 2000; Yule et al., 2000). Studies of the progression of behavior problems in children after disasters suggest that, although behavior problems may increase after exposure to a traumatic event, there may be a period after a disaster during which children actually behave better (McFarlane, Policansky, \& Irwin, 1987; Shaw et al., 1995). Among the factors thought to influence children's reactions to disasters are personal and family characteristics (Foy, Madvig, Pynoos, \& Camilleri, 1996; McFarlane et al., 1987), exposure to the event (Goenjian et al., 1995; March, Amaya-Jackson, Terry, \& Costanzo, 1997; Pynoos et al., 1987), and characteristics of the recovery environment (Pfefferbaum \& Pfefferbaum, 1998). 
In this analysis, we examine changes in children's behavior problems after the September 11 attacks. We compare the prevalence of behavior problems among children in NYC, as reported by parents in two independent surveys conducted 4 months and 6 months after the September 11 attacks, with parental reports of behavior problems among children documented in an NYC survey conducted 11 months prior to September 11. We explore the correlates of behavior problems, including demographic characteristics, the child's disaster experiences, and parental response to the event at 4 and 6 months postevent.

\section{Method}

\section{Data}

Post-September 11 data are from two cross-sectional random-digit-dial (RDD) telephone surveys with adults (18 years of age or older) conducted by the New York Academy of Medicine (NYAM) between January 15 and February 21, 2002, and between March 25 and June 25, 2002 (i.e., 4 and 6 months after the attacks, respectively). The sampling frame for the 4-month survey was all adults in NYC. For the 6-month survey, the sampling frame was all adults in the NYC metropolitan area, including parts of adjacent New Jersey and Connecticut, with an oversampling of NYC to permit comparisons between surveys. In both surveys, an adult in the household was randomly selected: The adult who had most recently had a birthday was chosen for participation. In the 4-month survey, 2,001 adults were interviewed, and in the 6-month survey, 2,752 adults were interviewed. Adults in both surveys who were the parent or primary caretaker of a child between the ages of 6 and 17 years who lived in the household were asked to respond to an additional set of questions about that child. Parents with more than one child in the appropriate age range were asked to respond to questions about the child who had most recently celebrated a birthday. Interviews were available in English and Spanish for the first survey and in English, Spanish, and Chinese for the second survey via computerassisted telephone interviewing. The cooperation rates were $64 \%$ for the 4-month survey and $56 \%$ for the 6-month survey. Sampling weights were developed and applied to the data to correct potential selection bias related to the number of telephones and children in the household and to adjust for sampling fractions. The study was approved by the institutional review board at NYAM.

Post-September 11 data were compared with pre-September 11 data on children living in NYC taken from the National Survey of America's Families (NSAF; Judkins, Brick, Broene, Ferraro, \& Strickler, 2000), a nationally representative, cross-sectional survey of over 45,000 households conducted between February and October 1999 (i.e., 11 months before the attacks). In the NSAF, information about one randomly selected child between the ages of 6 and 17 years was provided by the adult in the household who was most knowledgeable about the child (typically the child's parent). An RDD computer-assisted telephone interview was supplemented with an area probability sample of nontelephone households. Information about 443 children in NYC was available from the NSAF and used in this analysis. Survey weights were developed to compensate for probability of selection into the sample. The Urban Institute and Child Trends developed the NSAF (Judkins et al., 2000).

\section{Instrument}

Respondents in both NYAM surveys were asked questions from a structured interview that was approximately 35 min in length. Parents were asked about demographic characteristics, including their race-ethnicity, the annual household income, the number of parents in the household, the number of children in the household, and their ZIP code of residence on September 11. Parents were also asked about the child's demographic characteristics and disaster-related experiences. Questions included the child's age and gender, whether the child saw the attacks in person or on TV, and whether the child had seen the parent crying about the attacks. Parents were asked how well they thought their child responded to the September 11 attacks. We asked about the death of relatives or family friends and parental involvement in the ongoing rescue efforts. We also assessed parents' PTSD when content-related symptoms were linked to the September 11 attacks and major depression. We measured PTSD using the National Women's Study (NWS; Resnick, Kilpatrick, Dansky, Saunders, \& Best, 1993) PTSD module. In a validation study, the NWS PTSD module had a coefficient of agreement with clinician-administered structured clinical interviews of .71 for current PTSD and .77 for lifetime PTSD (Kilpatrick et al., 1998). A modified version of the Structured Clinical Interview for $D S M-I V$ for a major depressive episode was used to determine the presence of depression (First, Spitzer, Williams, \& Gibbon, 1997; Kilpatrick, Saunders, \& Smith, 2001).

In the NYAM surveys, we used the measure of child behavior developed for the NSAF to allow for pre- and post-September 11 comparisons. This standardized scale, designed to be administered to parents (Ehrle \& Moore, 1999), is a shortened version of the Child Behavior Checklist (Achenbach \& Ruffle, 2000). In all three surveys, parents of children ages 6 to 17 years were asked to indicate how often in the previous month their child had not gotten along with other kids; could not concentrate or pay attention for long; or had been unhappy, sad, or depressed. Parents of a 6- to 11-year-old were also asked how often their child felt worthless or inferior; had been nervous, high strung, or tense; or acted too young for his or her age. Parents of a 12- to 17-year-old were also asked whether the child had trouble sleeping, lied or cheated, or did poorly on his or her schoolwork. In the NSAF, the alpha coefficient was .73 for the scale constructed for children ages $6-11$ years and .75 for the scale for children ages 12-17 years. For each item, parents had 
three response choices: often true (3), sometimes true (2), and never true (1). We summed responses to create a behavior problem scale ranging from 6 to 18 . We used a cut-off score of 15 to indicate that the child had a moderate to high level of behavior problems.

\section{Statistical Analyses}

All analyses were carried out separately for children ages 6-11 years and ages $12-17$ years. We compared the demographic characteristics and behavior problems of children living only in the five boroughs of NYC using the pre-September 11 NSAF sample, the sample from the NYAM survey conducted 4 months after September 11, and the NYC sample of the NYAM survey conducted 6 months after September 11. However, we explored the correlates of behavior problems among all children in the NYAM surveys. Thus, the analysis of correlates of child behavior problems 4 months postevent included only children living in NYC, but the analysis at 6 months also included children from the greater New York metropolitan area. In bivariate analyses, we assessed the relations among child disaster event experiences, parental mental health, child demographics, and behavior problems. We calculated crude odds ratios (ORs) and 95\% confidence intervals (CIs) for all bivariate associations. We used multivariable logistic regression models to identify the independent relationship of key covariates with behavior problems, using all of the variables of interest in the final model. Analyses involving the broader geographic sample at 6 months included a control variable for residence in NYC (as opposed to the greater metropolitan area) on September 11. For all analyses, we used a threshold of $p<.05$ to determine statistical significance.

\section{Results}

\section{Sample Description}

In Table 1 we compare demographic characteristics of children living in NYC from the NSAF 11 months before September 11 with the demographics of children included in the NYAM surveys completed 4 months and 6 months after September 11. Comparisons among the three surveys reveal reasonably comparable demographic characteristics.

Table 1

Demographics of the Study Populations

\begin{tabular}{|c|c|c|c|c|c|c|c|c|c|c|c|c|}
\hline \multirow[b]{4}{*}{ Total } & \multicolumn{6}{|c|}{ 6-11-year-olds } & \multicolumn{6}{|c|}{ 12-17-year-olds } \\
\hline & \multirow{2}{*}{\multicolumn{2}{|c|}{$\begin{array}{c}\text { NSAF } 11 \\
\text { months } \\
\text { before 9/11 } \\
(n=220)\end{array}$}} & \multicolumn{4}{|c|}{ NYAM surveys } & \multirow{2}{*}{\multicolumn{2}{|c|}{$\begin{array}{c}\text { NSAF } 11 \\
\text { months } \\
\text { before } 9 / 11 \\
(n=223)\end{array}$}} & \multicolumn{4}{|c|}{ NYAM surveys } \\
\hline & & & \multicolumn{2}{|c|}{$\begin{array}{l}4 \text { months } \\
\text { after } 9 / 11 \\
(n=182)\end{array}$} & \multicolumn{2}{|c|}{$\begin{array}{l}6 \text { months } \\
\text { after } 9 / 11 \\
(n=110)\end{array}$} & & & \multicolumn{2}{|c|}{$\begin{array}{l}4 \text { months } \\
\text { after } 9 / 11 \\
(n=178)\end{array}$} & \multicolumn{2}{|c|}{$\begin{array}{l}6 \text { months } \\
\text { after } 9 / 11 \\
(n=134)\end{array}$} \\
\hline & $n$ & $\%$ & $n$ & $\%$ & $n$ & $\%$ & $n$ & $\%$ & $n$ & $\%$ & $n$ & $\%$ \\
\hline \multicolumn{13}{|l|}{ Gender of child } \\
\hline Male & 106 & 46.3 & 97 & 56.5 & 59 & 55.7 & 115 & 55.0 & 100 & 52.5 & 74 & 55.3 \\
\hline Female & 114 & 53.7 & 85 & 43.5 & 51 & 44.3 & 118 & 45.0 & 78 & 47.5 & 59 & 49.7 \\
\hline \multicolumn{13}{|l|}{ Race of child } \\
\hline White & 49 & 29.5 & 55 & 30.5 & 35 & 24.3 & 51 & 20.7 & 58 & 28.8 & 49 & 33.1 \\
\hline African American & 72 & 30.0 & 62 & 35.0 & 23 & 27.1 & 73 & 32.4 & 63 & 38.5 & 38 & 35.2 \\
\hline Hispanic & 88 & 33.9 & 54 & 29.2 & 37 & 37.0 & 95 & 36.3 & 44 & 25.3 & 35 & 26.2 \\
\hline Other & 11 & 6.5 & 10 & 5.3 & 14 & 11.6 & 14 & 10.7 & 11 & 7.4 & 11 & 5.6 \\
\hline \multicolumn{13}{|l|}{ Child has siblings } \\
\hline No & 56 & 18.0 & 70 & 22.2 & 59 & 30.3 & 103 & 29.5 & 89 & 27.9 & 71 & 29.1 \\
\hline Yes & 164 & 82.0 & 112 & 77.8 & 51 & 69.7 & 130 & 70.5 & 89 & 72.1 & 63 & 70.9 \\
\hline \multicolumn{13}{|l|}{ Household income } \\
\hline Less than $\$ 20,000$ & 85 & 36.5 & 26 & 18.0 & 26 & 21.8 & 76 & 35.4 & 20 & 18.1 & 31 & 33.4 \\
\hline$\$ 20,001-\$ 40,000$ & 56 & 21.7 & 50 & 35.8 & 22 & 28.5 & 60 & 28.1 & 49 & 33.0 & 36 & 31.1 \\
\hline$\$ 40,001-\$ 75,000$ & 51 & 27.9 & 45 & 25.6 & 24 & 31.3 & 47 & 16.6 & 43 & 28.0 & 30 & 23.7 \\
\hline$\$ 75,001$ or more & 28 & 13.9 & 33 & 20.6 & 24 & 18.4 & 50 & 19.9 & 38 & 21.0 & 23 & 11.8 \\
\hline \multicolumn{13}{|c|}{ Single-parent household } \\
\hline No & 116 & 57.0 & 114 & 63.6 & 66 & 66.9 & 122 & 50.9 & 107 & 64.8 & 74 & 52.3 \\
\hline Yes & 104 & 43.0 & 67 & 36.4 & 44 & 33.1 & 111 & 49.1 & 70 & 35.2 & 60 & 47.7 \\
\hline
\end{tabular}

Note. Because of missing data, values may not sum to the reported sample size. The National Survey of America's Families (NSAF) is a nationally representative, cross-sectional survey of over 45,000 households that took place between February and October 1999. The New York Academy of Medicine (NYAM) is a nonprofit organization in New York City carrying out a series of surveys of New York City residents to assess the psychological impact of the September 11, 2001, (9/11) attacks. 


\section{Prevalence of Behavior Problems at Three Time Points}

Table 2 shows the prevalence of behavior problems at three time points (11 months prior to September 11, according the NSAF, and 4 months and 6 months after September 11, according to the NYAM surveys), as reported by parents. Thirty-three percent of children ages 6-11 years were reported to have behavior problems 11 months prior to September 11 . However, 4 months after September 11, the prevalence of behavior problems among 6- to 11-year-olds was $19 \%$, and, at 6 months after September 11, the prevalence of behavior problems among 6- to 11year-olds was $33 \%$. Thirty-eight percent of 12- to 17-year-olds were reported to have behavior problems before September 11. This prevalence was $29 \%$ when assessed 4 months after September 11 and 44\% when assessed 6 months after September 11.

\section{Bivariate Correlates of Behavior Problems in Children 4 Months After the September 11 Attacks}

In bivariate analyses, five covariates were significantly associated with behavior problems among 6to 11-year-olds 4 months after the September 11 attacks. Children in households in which the combined income in 2001 was $\$ 40,000-\$ 75,000$, as compared with less than $\$ 20,000$, were less likely to have behavior problems ( $\mathrm{OR}=0.11,95 \%$ $\mathrm{CI}=0.02,0.55)$. Children in households in which a relative or friend of the family was killed $(\mathrm{OR}=0.09,95 \% \mathrm{CI}=0.01,0.68)$ were also less likely to have behavior problems. By contrast, chil- dren living in single-parent or primary caretaker households were more likely to have behavior problems $(\mathrm{OR}=4.56,95 \% \mathrm{CI}=1.96,10.64)$, as were children whose parents or primary caretakers had less knowledge of how their child was responding to the September 11 attacks (OR $=3.95,95 \%$ $\mathrm{CI}=1.41,11.21)$ and children whose parents or primary caretaker had PTSD or depression $(\mathrm{OR}=6.04,95 \% \mathrm{CI}=2.00,18.28)$.

In bivariate analyses, being African American versus White $(\mathrm{OR}=5.10,95 \% \mathrm{CI}=1.92,13.58)$, being Hispanic versus White $(\mathrm{OR}=3.90,95 \%$ $\mathrm{CI}=1.39,10.99)$, and having a parent or primary caretaker involved in the ongoing rescue efforts $(\mathrm{OR}=7.59,95 \% \mathrm{CI}=2.08,27.66)$ were associated with behavior problems 4 months after September 11 for children ages 12 to 17 years. Parents or primary caretakers who knew less about how their adolescent was responding to the September 11 attacks were also more likely to say their adolescent was experiencing behavior problems $(\mathrm{OR}=3.95,95 \%$ $\mathrm{CI}=1.41,11.21)$.

\section{Multivariable Correlates of Behavior Problems in Children 4 Months After the September 11 Attacks}

In a multivariable logistic regression model, the following factors were associated with behavior problems among children ages 6-11 years 4 months after September 11 (see Table 3). Children in households in which the combined income in 2001 was $\$ 40,000-\$ 75,000$, as compared with less than $\$ 20,000$, were less likely to have behavior problems $(\mathrm{OR}=0.11,95 \% \mathrm{CI}=0.02,0.60)$, as were children

Table 2

Prevalence of Behavior Problems in Children at Three Points in Time

\begin{tabular}{|c|c|c|c|c|c|c|c|c|c|c|c|c|}
\hline \multirow{4}{*}{$\begin{array}{l}\text { Child behavior } \\
\text { problems }\end{array}$} & \multicolumn{6}{|c|}{ 6-11-year-olds } & \multicolumn{6}{|c|}{ 12-17-year-olds } \\
\hline & \multirow{2}{*}{\multicolumn{2}{|c|}{$\begin{array}{c}\text { NSAF } 11 \\
\text { months } \\
\text { before } 9 / 11 \\
(n=220)\end{array}$}} & \multicolumn{4}{|c|}{ NYAM surveys } & \multirow{2}{*}{\multicolumn{2}{|c|}{$\begin{array}{c}\text { NSAF } 11 \\
\text { months } \\
\text { before 9/11 } \\
(n=223)\end{array}$}} & \multicolumn{4}{|c|}{ NYAM surveys } \\
\hline & & & \multicolumn{2}{|c|}{$\begin{array}{l}4 \text { months } \\
\text { after } 9 / 11 \\
(n=182)\end{array}$} & \multicolumn{2}{|c|}{$\begin{array}{l}6 \text { months } \\
\text { after } 9 / 11 \\
(n=110)\end{array}$} & & & \multicolumn{2}{|c|}{$\begin{array}{l}4 \text { months } \\
\text { after } 9 / 11 \\
(n=178)\end{array}$} & \multicolumn{2}{|c|}{$\begin{array}{l}6 \text { months } \\
\text { after } 9 / 11 \\
(n=134)\end{array}$} \\
\hline & $n$ & $\%$ & $n$ & $\%$ & $n$ & $\%$ & $n$ & $\%$ & $n$ & $\%$ & $n$ & $\%$ \\
\hline No & 146 & 67.1 & 148 & 81.4 & 69 & 66.9 & 149 & 62.4 & 125 & 71.0 & 78 & 56.2 \\
\hline Yes & 74 & 32.9 & 34 & $18.7^{*}$ & 41 & 33.1 & 84 & 37.6 & 53 & $29.0 *$ & 56 & 43.9 \\
\hline
\end{tabular}

Note. Because of missing data, values may not sum to the reported sample size. The National Survey of America's Families (NSAF) is a nationally representative, cross-sectional survey of over 45,000 households that took place between February and October 1999. The New York Academy of Medicine (NYAM) is a nonprofit organization in New York City carrying out a series of surveys of New York City residents to assess the psychological impact of the September 11, 2001, $(9 / 11)$ attacks.

$* p<.05$. 
Table 3

Multivariable Predictors of Moderate to High Levels of Behavior Problems 4 Months After the September 11, 2001, Attacks

\begin{tabular}{|c|c|c|c|c|c|c|}
\hline \multirow[b]{2}{*}{ Predictor } & \multicolumn{3}{|c|}{ 6-11-year-olds $(n=182)$} & \multicolumn{3}{|c|}{$12-17$-year-olds $(n=178)$} \\
\hline & OR & $95 \% \mathrm{CI}$ & $p$ & OR & $95 \% \mathrm{CI}$ & $p$ \\
\hline \multicolumn{7}{|l|}{ Demographic characteristics } \\
\hline \multicolumn{7}{|l|}{ Gender of child } \\
\hline Male & - & - & - & - & - & - \\
\hline Female & 0.73 & $0.25, \quad 2.11$ & .56 & 0.53 & $0.04, \quad 8.56$ & .25 \\
\hline \multicolumn{7}{|l|}{ Race of child } \\
\hline White & - & - & - & - & - & - \\
\hline African American & 1.26 & $0.17, \quad 9.31$ & .82 & 3.49 & $1.02,11.96$ & .05 \\
\hline Hispanic & 1.62 & $0.22, \quad 11.90$ & .64 & 1.41 & $0.30, \quad 6.53$ & .66 \\
\hline Other & 21.20 & $2.53,177.39$ & .01 & 2.93 & $0.32,26.80$ & .34 \\
\hline \multicolumn{7}{|l|}{ Child has siblings } \\
\hline No & - & - & - & - & - & - \\
\hline Yes & 1.29 & $0.35, \quad 4.78$ & .71 & 0.74 & $0.26, \quad 2.09$ & .57 \\
\hline \multicolumn{7}{|l|}{ Household income } \\
\hline Less than $\$ 20,000$ & - & - & - & - & - & - \\
\hline$\$ 20,001-\$ 40,000$ & 0.29 & $0.06, \quad 1.39$ & .12 & 0.17 & $0.03, \quad 0.90$ & .04 \\
\hline$\$ 40,001-\$ 75,000$ & 0.11 & $0.02, \quad 0.60$ & .01 & 0.21 & $0.03, \quad 1.70$ & .14 \\
\hline$\$ 75,001$ or more & 0.12 & $0.02, \quad 0.65$ & .01 & 0.26 & $0.02, \quad 3.10$ & .28 \\
\hline \multicolumn{7}{|l|}{ Single parent household } \\
\hline No & - & - & - & - & - & - \\
\hline Yes & 3.30 & $1.11, \quad 9.80$ & .03 & 0.45 & $0.09, \quad 2.30$ & .34 \\
\hline \multicolumn{7}{|l|}{ Disaster experiences } \\
\hline \multicolumn{7}{|l|}{ Child saw attacks in person } \\
\hline No & - & - & - & - & - & - \\
\hline Yes & 0.68 & $0.21, \quad 2.23$ & .52 & 1.14 & $0.41, \quad 3.16$ & .79 \\
\hline \multicolumn{7}{|c|}{ Child saw parent cry about the attacks } \\
\hline No & - & - & - & - & - & - \\
\hline Yes & 0.79 & $0.25, \quad 2.49$ & .68 & 2.18 & $0.62,7.61$ & .22 \\
\hline \multicolumn{7}{|c|}{ Relative or friend of the family was killed } \\
\hline No & - & - & - & - & - & - \\
\hline Yes & 0.08 & $0.00, \quad 1.59$ & .10 & 1.54 & $0.46, \quad 5.09$ & .48 \\
\hline \multicolumn{7}{|c|}{ Parent involved in rescue effort } \\
\hline No & - & - & - & - & - & - \\
\hline Yes & 1.41 & $0.36, \quad 5.49$ & 62 & 4.01 & $1.00,16.01$ & .05 \\
\hline \multicolumn{7}{|c|}{ Parent knows how child is responding } \\
\hline Well & - & - & - & - & - & - \\
\hline Not well & 4.36 & $1.38, \quad 13.72$ & .01 & 7.37 & $2.36,23.02$ & .01 \\
\hline \multicolumn{7}{|c|}{ Parental PTSD or depression } \\
\hline No & - & - & - & - & - & - \\
\hline Yes & 6.85 & $1.51,31.10$ & .01 & 1.72 & $0.36, \quad 8.29$ & .50 \\
\hline
\end{tabular}

Note. Dashes indicate the category within each variable that is the referent group. $\mathrm{OR}=$ odds ratio; $\mathrm{CI}=$ confidence interval; PTSD = posttraumatic stress disorder.

in households in which the combined income was more than $\$ 75,000$ in 2001 (OR $=0.12,95 \%$ $\mathrm{CI}=0.02,0.65)$. Children in single-parent households were more likely to have behavior problems $(\mathrm{OR}=3.30,95 \% \mathrm{CI}=1.11,9.80)$, as were children whose parents had less knowledge of how their child was responding to the September 11 attacks $(\mathrm{OR}=4.36,95 \% \mathrm{CI}=1.38,13.72)$ and children whose parents had PTSD or depression linked to the September 11 attacks $(\mathrm{OR}=6.85,95 \%$ $\mathrm{CI}=1.51,31.10)$.
In the multivariable adjusted model of 12- to 17-yearolds 4 months after the attacks, three factors were associated with behavior problems (see Table 3). Two of these factors were being African American versus White $(\mathrm{OR}=3.49,95 \% \mathrm{CI}=1.02,11.96)$ and having a parent involved in the ongoing rescue efforts $(\mathrm{OR}=4.01,95 \% \mathrm{CI}=1.00,16.01)$. Parents who knew less well how their adolescent was responding to the September 11 attacks were also more likely to say their adolescent was experiencing behavior problems $(\mathrm{OR}=7.37,95 \% \mathrm{CI}=2.36,23.02)$. 
Bivariate Correlates of Behavior

\section{Problems in Children 6 Months After the September 11 Attacks}

Six to 9 months after the September 11 attacks, there were fewer significant correlates of behavior problems in children ages 6-11 years, compared with 4 months postevent. In bivariate analyses, being a single parent $(\mathrm{OR}=2.19,95 \% \mathrm{CI}=1.01,4.72)$ was the only significant factor associated with behavior problems in children ages 6-11 years.

By contrast, several significant correlates of behavior problems were identified among 12- to 17year-olds at 6 months postevent in bivariate analysis. African American adolescents, compared with White adolescents, were more likely to have behavior problems $(\mathrm{OR}=2.39,95 \% \mathrm{CI}=0.97$, 5.92). Adolescents in households in which the combined income the previous year was more than $\$ 75,000$ were less likely than adolescents in households with an income below $\$ 20,000$ to have behavior problems $(\mathrm{OR}=0.34,95 \% \mathrm{CI}=0.12$, 0.91). Adolescents in single-parent households were more likely to have behavior problems $(\mathrm{OR}=3.02,95 \% \mathrm{CI}=1.49,6.13)$. Adolescents who lived in NYC, compared with outside of NYC, were more likely to have behavior problems $(\mathrm{OR}=2.00,95 \% \mathrm{CI}=0.99,4.05)$. Adolescents who saw a parent cry about the September 11 attacks were more likely to have behavior problems $(\mathrm{OR}=2.09,95 \% \mathrm{CI}=0.97,4.49)$, as were adolescents whose parents had PTSD or depression $(\mathrm{OR}=3.87,95 \% \mathrm{CI}=1.39,10.78)$.

\section{Multivariable Correlates of Behavior Problems in Children 6 Months After the September 11 Attacks}

In multivariable analyses 6 months after September 11 , no factors were associated with behavior problems in children ages 6-11 years (see Table 4). However, in multivariable analyses 6 to 9 months postevent, two factors were significantly associated with behavior problems in children ages 12-17 years. Adolescents who saw a parent cry were more likely to have a moderate to high level of problems $(\mathrm{OR}=3.61,95 \% \mathrm{CI}=1.56,8.36)$, and those living in households in which a friend or relative had been killed were less likely to have behavior problems $(\mathrm{OR}=0.28,95 \%$ $\mathrm{CI}=0.09,0.93$; see Table 4).

\section{Discussion}

Using data from two cross-sectional surveys of NYC parents conducted 4 months and 6 months after the September 11 attacks and comparing these results with a baseline survey conducted 11 months before September 11, we found that, among both children ages $6-11$ years and adolescents ages 12-17 years, the prevalence of behavior problems had decreased 4 months after September 11 but had returned to predisaster levels 6 months after September 11. In addition, we found that child demographic characteristics (i.e., income, single-parent household, race-ethnicity), disaster experiences, and parental reactions to the attacks were associated with child behavior problems in multivariable models.

\section{Prevalence of Child Behavior Problems After a Traumatic Event}

Our finding that children were reportedly behaving better 4 months after the September 11 attacks compared with 1999 levels is consistent with other longitudinal studies of psychological morbidity in children following disasters. A study of children followed for 21 months after exposure to Hurricane Andrew found an initial decrease in nonPTSD emotional and behavioral problems in children residing in the area hardest hit by the hurricane, with a return to normal levels of behavioral problems after the event (Shaw et al., 1995, 1996). Contrary to the authors' prediction, a study of 808 children after a bush fire disaster found that the prevalence of behavior problems in children exposed to the disaster was less than the prevalence in a carefully selected comparison group 2 months after the event (McFarlane et al., 1987). Other studies have found increased behavior problems in children after disasters, which suggests that patterns of morbidity may change over time and may have a delayed onset (McFarlane et al., 1987; Najarian, Goenjian, Pelcovitz, Mandel, \& Najarian, 1996).

One explanation that has been suggested for the decreased prevalence of behavior problems in children in the immediate aftermath of a disaster is numbing or a dampened behavioral response (Shaw et al., 1995). Because our study is based on interviews with parents rather than on direct assessments of children, we are unable to determine whether the reduced prevalence of behavior problems 4 months after the Septem- 
Table 4

Multivariable Predictors of Moderate to High Levels of Behavior Problems 6 Months After the September 11, 2001, Attacks

\begin{tabular}{|c|c|c|c|c|c|c|}
\hline \multirow[b]{2}{*}{ Predictor } & \multicolumn{3}{|c|}{ 6-11-year-olds $(n=205)$} & \multicolumn{3}{|c|}{$12-17$-year-olds $(n=249)$} \\
\hline & OR & $95 \% \mathrm{CI}$ & $p$ & OR & $95 \% \mathrm{CI}$ & $p$ \\
\hline \multicolumn{7}{|l|}{ Demographic characteristics } \\
\hline \multicolumn{7}{|l|}{ Gender of child } \\
\hline Male & - & - & - & - & - & - \\
\hline Female & 1.48 & $0.63,3.47$ & .37 & 0.75 & $0.32,1.76$ & .51 \\
\hline \multicolumn{7}{|l|}{ Race of child } \\
\hline White & - & - & - & - & - & - \\
\hline African American & 0.66 & $0.18,2.45$ & .54 & 1.48 & $0.38,5.79$ & .57 \\
\hline Hispanic & 0.26 & $0.07,0.96$ & .04 & 1.14 & $0.34,3.89$ & .83 \\
\hline Other & 0.64 & $0.14,2.95$ & .57 & 2.56 & $0.68,9.73$ & .17 \\
\hline \multicolumn{7}{|l|}{ Child has siblings } \\
\hline No & - & - & - & - & - & - \\
\hline Yes & 1.32 & $0.46,3.80$ & .60 & 0.73 & $0.33,1.59$ & .42 \\
\hline \multicolumn{7}{|l|}{ Household income } \\
\hline Less than $\$ 20,000$ & - & - & - & - & - & - \\
\hline$\$ 20,001-\$ 40,000$ & 0.69 & $0.16,2.96$ & 62 & 0.73 & $0.20,2.76$ & .65 \\
\hline$\$ 40,001-75,000$ & 0.70 & $0.18,2.70$ & .60 & 0.82 & $0.21,3.17$ & .78 \\
\hline$\$ 75,001$ or more & 0.51 & $0.12,2.09$ & .35 & 0.76 & $0.17,3.37$ & .71 \\
\hline \multicolumn{7}{|l|}{ Lived in NYC on $9 / 11$} \\
\hline No & - & - & - & - & - & - \\
\hline Yes & 0.74 & $0.27,2.01$ & .56 & 1.26 & $0.50,3.19$ & .13 \\
\hline \multicolumn{7}{|l|}{ Single-parent household } \\
\hline No & - & - & - & - & - & - \\
\hline Yes & 1.49 & $0.48,4.65$ & .49 & 2.27 & $0.79,6.49$ & .62 \\
\hline \multicolumn{7}{|l|}{ Disaster experiences } \\
\hline \multicolumn{7}{|l|}{ Child saw attacks in person } \\
\hline No & - & - & - & - & - & - \\
\hline Yes & 0.66 & $0.28,1.58$ & .35 & 0.54 & $0.22,1.35$ & .19 \\
\hline \multicolumn{7}{|c|}{ Child saw parent cry about the attacks } \\
\hline No & - & - & - & - & - & - \\
\hline Yes & 1.49 & $0.62,3.56$ & .37 & 3.61 & $1.56,8.36$ & .01 \\
\hline \multicolumn{7}{|c|}{ Relative or friend of the family was killed } \\
\hline No & - & - & - & - & - & - \\
\hline Yes & 1.43 & $0.50,4.06$ & .50 & 0.28 & $0.09,0.93$ & .04 \\
\hline \multicolumn{7}{|c|}{ Parent involved in rescue effort } \\
\hline No & - & - & - & - & - & - \\
\hline Yes & 1.02 & $0.17,5.98$ & .99 & 1.73 & $0.45,6.70$ & .42 \\
\hline \multicolumn{7}{|c|}{ Parent knows how child is responding } \\
\hline Well & - & - & - & - & - & - \\
\hline Not well & 2.11 & $0.54,8.26$ & .28 & 2.32 & $0.97,5.54$ & .34 \\
\hline \multicolumn{7}{|c|}{ Parental PTSD or depression } \\
\hline No & - & - & - & - & - & - \\
\hline Yes & 2.26 & $0.83,6.18$ & .11 & 2.02 & $0.48,8.58$ & .06 \\
\hline
\end{tabular}

Note. Dashes indicate the category within each variable that is the referent group. $\mathrm{OR}=$ odds ratio; $\mathrm{CI}=$ confidence interval; NYC $=$ New York City; 9/11 = September 11, 2001; PTSD = posttraumatic stress disorder.

ber 11 attacks reflects a desire on the part of parents to assess their child's behavior more positively or an actual change in behavior, as suggested by these other studies. We cannot discount the possibility that parents might have been less willing to identify negative aspects of their child's behavior because of the increased stress their child was under. Alternatively, children might have behaved better because they were afraid or because they sensed that their parents were stressed. In either case, our finding of a decreased prevalence of behavior problems in the first few months after the September 11 terrorist attacks is important, because the identification of children who need mental health treatment may be complicated by a dampened behavioral response or by a decreased sensitivity of parental assessment to behavioral problems. 


\section{The Relationship Between Parent and Child Behavior}

The finding that parental reactions to the September 11 attacks were associated with behavioral responses in the children is supported by other studies completed after September 11 that showed an association between adverse psychological sequelae in parents and in their children. In a national telephone survey after the September 11 attacks that used parent report, parents with stress reactions were found to be more likely than others to report stress in their children (Schuster et al., 2001). In a survey of parents completed 4 months after the September 11 attacks, the authors found a strong association between parental PTSD and posttraumatic stress reactions in children (Fairbrother, Stuber, Galea, Fleischman, \& Pfefferbaum, 2003). These findings are consistent with a broader literature showing a strong relationship between parental distress and children's distress (Earls et al., 1988; Brenton, Valla, \& Lambert, 1993; de Vries et al., 1999).

However, it is possible that parental distress might have biased parents' perceptions of their children's behavior problems. Considerable controversy exists regarding the possible influence of parental depression, particularly maternal depression, on reports of children's symptomatology. In some studies, parents who are distressed have been shown to overestimate their child's symptomatology, whereas in other studies distressed parents have underestimated their child's symptomatology (Angold et al., 1987; Breslau, Davis, \& Prabucki, 1988; Conrad \& Hammen, 1989). Behavioral problems in children also might have affected parental reactions to a disaster, or some past or current factor, such as prior psychiatric conditions, prior trauma, or underlying stress, might have influenced the reactions of both parents and children. Although definitive clarification of this issue requires longitudinal data collected from both parents and children, these results, taken in concert with previous findings, suggest a link between parents' mental health and behavior problems in children.

A related finding that parents who reported they did not know how their child was responding to the September 11 attacks were more likely to report behavior problems in their children suggests that parents should discuss traumatic events, such as the September 11 attacks, with their children, although we make this recommendation cautiously in light of the limitations of inference regarding the direction of causality inherent in these analyses. Additional re- search is needed to determine the most effective ways for parents to discuss future acts of terrorism with their children and to identify other parenting practices that may mitigate children's negative psychological response to traumatic events.

Adolescents ages 12-17 years whose parents were involved in rescue and recovery efforts were more likely to have behavior problems 4 months after the attacks. This relationship was maintained even when we controlled for parental PTSD and depression. One possible explanation is that parents involved in recovery efforts may provide less emotional support to their children because of their own stress. It is also interesting to note that parental involvement in the recovery efforts was associated with adolescent behavior problems but not behavior problems in 6- to 11-year-olds. This may be due to a greater awareness, as a result of maturation, of the dangers associated with the rescue efforts.

Furthermore, adolescents who saw a parent crying were more likely to have behavior problems 6 months after September 11, compared with other adolescents. Although, generally, it is thought that age-appropriate discussions and sharing of emotions between parents and children about tragic events are beneficial to children (Leavitt, 2002; Melnky et al., 2002), our results suggest that seeing their parents crying about the September 11 attacks had an adverse effect on children's behavior. Parental crying may especially affect children's behavioral well-being, because children may see it as an indication that the parent is overwhelmed and stressed. Perhaps this finding is context specific. Parental crying may validate a child's reaction to a natural disaster or other isolated tragic events but may be harmful in those instances, such as the September 11 attacks, in which fear and uncertainty are sustained.

\section{Subgroups Most Vulnerable to Traumatic Events}

Socially disadvantaged children, such as those in single-parent families or those living in poor families, have been shown by prior research to be more likely than other children to have behavior problems (Chase-Lansdale \& Hetherington, 1990; Duncan, Brooks-Gunn, \& Klebanov, 1994). Our samples were too small to investigate whether socially disadvantaged groups of children or children of racial or ethnic minorities were more vulnerable than other children to the September 11 attacks, although it is interesting that there were some associations between single parenthood, household income, and race, on 
the one hand, and behavior problems, on the other hand, 4 months after September 11. This finding suggests that children of demographically disadvantaged families may be particularly vulnerable to the negative consequences to their behavioral well-being than are other children.

\section{Limitations}

Our findings are limited by several factors. First, we did not assess children directly. Studies have shown limited correspondence between parental reports and independent children's reports of mental health symptoms and/or diagnoses (Daviss et al., 2000; Earls et al., 1988). We used a behavioral indicator of distress because parents have been shown to more accurately assess behavior problems than children's internalizing symptoms (Cytryn \& McKnew, 1980; Edelbrock, Costello, Dulcan, Conover, \& Kalas, 1986; Eiser \& Morse, 2001; Najman et al., 2001). However, some discrepancies between parents' and children's assessments of the child's behavior have also been reported (Hutchinson et al., 2001; Najman et al., 2001). We note that previous psychometric work on the behavior scale used in this study showed a high level of correspondence between child and parent reports (Child Trends \& Ohio State University Center for Human Resource Research, 1999).

A second limitation is that we used data from three separate cross-sectional samples. Because the impact of a disaster such as the September 11 attacks on any individual child may evolve over time, a definitive assessment of the progression of child behavior after a disaster requires a longitudinal assessment. Although our data provide estimates of the changing prevalence of behavior problems at different time points, we cannot use them to draw inferences about the progression of behavior in individual children, nor can we draw causal inferences about the observed relations between the covariates of interest and behavior problems. Given the limited availability of longitudinal data examining children's responses after disasters, having access to three cross-sectional data sets with reasonably comparable demographic characteristics and identical measures of behavior assessed before and after the disaster is extremely important. However, we cannot rule out the possibility that differences in sample characteristics among surveys could account for some of the observed differences in behavior problems 4 months after the September 11 attacks.

The fact that baseline and postevent data came from separate surveys is also a limitation, because different methodologies used in the NSAF and the NYAM surveys might have affected interviewee responses. For example, there were differences in survey length (25-45 $\mathrm{min}$ in the NSAF vs. $35 \mathrm{~min}$ in the NYAM surveys), the subject matter covered by the surveys, question order, and interviewer training, all of which could have affected respondent burden and/or survey responses. The NYAM surveys tried to reduce these potential problems by matching the NSAF methodology as closely as possible. Despite these differences, the similar levels of behavior problems observed 11 months prior to the September 11 attacks and those measured in the NYAM survey 6 months after the event suggest that the survey measures were comparable.

In addition to behavior problems, PTSD, anxiety, and depression have been documented as problems in children following exposure to a traumatic event. We were not able to draw inferences about these conditions in this study. Additional research should examine the longitudinal course of these problems in children following exposure to a mass-scale traumatic event as well as other possible determinants of behavior problems (e.g., peritraumatic dissociation, degree of upheaval in the child's life after a disaster) that are not measured in this study.

\section{Clinical Implications}

Our finding that the identification of children who need mental health treatment may be complicated by a dampened behavioral response or by a decreased sensitivity of parental assessment to behavioral problems suggests that children who are adversely affected by a disaster may not be identified easily for services. Parents may need more education to identify psychological distress in their children, because they serve as gatekeepers to mental health services for children and their perceptions are essential to the accurate diagnosis of children's mental health problems (Offord et al., 1987). In addition, mental health professionals and pediatricians should be attuned to the link between parental and child mental health. It is possible that a child's recovery after a traumatic event might be hampered if the parent's symptoms are not also treated. Family-oriented treatment may be in order, and children's health care providers should be able to make referrals for parents to mental health professionals. Mental health professionals and pediatricians should also be aware of the potential influence of parents' mental health on parental reporting, which underscores the need for direct assess- 
ment and screening of children for psychological distress in clinical settings after disasters.

\section{References}

Achenbach, T. M., \& Ruffle, T. M. (2000). The Child Behavior Checklist and related forms for assessing behavioral/emotional problems and competencies. Pediatrics in Review, 21, 265-271.

Angold, A., Weissman, M. M., John, K., Merikangas, K. R., Prusoff, B. A., Wickramarante, P., et al. (1987). Parent and child reports of depressive symptoms in children at low and high risk of depression. Journal of Child Psychology and Psychiatry 28, 901-915.

Bolton, D., O'Ryan, D., \& Udwin, O. (2000). The long-term psychological effects of a disaster experienced in adolescence: II. General psychopathology. Journal of Child Psychology and Psychiatry, 41, 513-523.

Brenton, J. J., Valla, J. P., \& Lambert, J. (1993). Industrial disaster and mental health of children and their parents. Journal of the American Academy of Child and Adolescent Psychiatry, 32, 438-445.

Breslau, N., Davis, G. C., \& Prabucki, K. (1988). Depressed mothers as informants in family history research-Are they accurate? Psychiatry Research, 24, 345-359.

Burke, J. D., Jr., Borus, J. F., \& Burns, B. J. (1982). Changes in children's behavior after a natural disaster. American Journal of Psychiatry, 139, 1010-1014.

Chase-Lansdale, P. L., \& Hetherington, E. M. (1990). The impact of divorce on life-span development: Short and long term effects. In P. B. Baltes, D. L. Featherma, \& R. M. Lernor (Eds.), Life span development and behavior (Vol. 10, pp. 105-150). Hillside, NJ: Erlbaum.

Child Trends \& Ohio State University Center for Human Resource Research. (1999). NLSY97 codebook supplement main file Round 2, Appendix 9: Family process and adolescent outcome measures. Washington, DC: U. S. Department of Labor.

Conrad, M., \& Hammen, C. (1989). Role of maternal depression in perceptions of child maladjustment. Journal of Consulting and Clinical Psychology, 57, 663-667.

Cytryn, L., \& McKnew, D. H. (1980). Affective disorders in childhood. In A. M. Freeman, H. I. Kaplan, \& B. H. Sadock (Eds.), Comprehensive textbook of psychiatry II (Vol. 3). Baltimore: Williams \& Wilkins.

Daviss, W. B., Racusin, R., Fleischer, A., Mooney, D., Ford, J. D., \& McHugo, G. J. (2000). Acute stress disorder symptomatology during hospitalization for pediatric injury. Journal of the American Academy of Child and Adolescent Psychiatry, 39, 569-575.

de Vries, A. P., Kassam-Adams, N., Cnaan, A., ShermanSlate, E., Gallagher, P. R., \& Winston, F. K. (1999). Looking beyond the physical injury: Posttraumatic stress disorder in children and parents after pediatric traffic injury. Pediatrics, 104, 1293-1299.

Duncan, G. J., Brooks-Gunn, J., \& Klebanov, P. K. (1994). Economic deprivation and early childhood development. Child Development, 65, 296-318.
Earls, F., Smith, E., Reich, W., \& Jung, K. G. (1988). Investigating psychopathological consequences of a disaster in children: A pilot study incorporating a structured diagnostic interview. Journal of the American Academy of Child and Adolescent Psychiatry, 27, 90-95.

Edelbrock, C., Costello, A. J., Dulcan, M. K., Conover, N. C., \& Kalas, R. (1986). Parent-child agreement on child psychiatric symptoms assessed via structured interview. Journal of Child Psychology and Psychiatry, 27, 181-190.

Ehrle, J., \& Moore, K. A. (1999). 1997 NSAF benchmarking measures of child and family well-being: Report No. 6. Retrieved February 10, 2005, from the Urban Institute Web site: http://www.urban.org/UploadedPDF/ Methodology_6.pdf

Eiser, C., \& Morse, R. (2001). Can parents rate their child's health-related quality of life? Results of a systematic review. Quality of Life Research, 10, 347-357.

Fairbrother, G., Stuber, J., Galea, S., Fleischman, A., \& Pfefferbaum, B. (2003). Posttraumatic stress reactions in New York City children after the September 11, 2001 terrorist attacks. Ambulatory Pediatrics, 3, 304-311.

First, M. B., Spitzer, R. L., Williams, J. B. W., \& Gibbon, M. (1997). A synthesis of the findings from the Quake Impact Study: A two-year investigation of the psychological sequelae of the 1989 Newcastle earthquake. Social Psychiatry and Psychiatric Epidemiology, 32, 123136.

Foy, D. W., Madvig, B. T., Pynoos, R. S., \& Camilleri, A. J. (1996). Etiologic factors in the development of posttraumatic stress disorder in children and adolescents. Journal of School Psychology, 34, 133-145.

Giaconia, R. M., Reinherz, H. Z., Silverman, A. B., Pakiz, B., Frost, A. K., \& Cohen, E. (1995). Traumas and posttraumatic stress disorder in a community population of older adolescents. Journal of the American Academy of Child and Adolescent Psychiatry, 34, 1369-1380.

Goenjian, A. K., Molina, L., Steinberg, A. M., Fairbanks, L. A., Alvarez, M. L., Goenjian, H. A., \& Pynoos, R. S. (2001). Posttraumatic stress and depressive reactions among Nicaraguan adolescents after Hurricane Mitch. American Journal of Psychiatry 158, 788-794.

Goenjian, A. K., Pynoos, R. S., Steinberg, A. M., Najarian, L. M., Asarnow, J. R., Karayan, I., et al. (1995). Psychiatric comorbidity in children after the 1988 earthquake in Armenia. Journal of the American Academy of Child and Adolescent Psychiatry, 34, 1174-1184.

Hoven, C. W., Mandell, D., \& Duarte, C. S. (2003). Mental health of New York City public school children after 9/11: An epidemiological investigation. In S. Coates, J. L. Rosenthal, \& D. S. Schechter (Eds.), September 11: Trauma and human bonds (pp. 51-74). Hillsdale, NJ: Analytic Press.

Hutchinson, E., Pearson, D., Fitzgerald, C., Bateman, B., Gant, C., Grundy, J., et al. (2001). Can parents accurately perceive hyperactivity in their child? Child: Care, Health and Development, 27, 241-250. 
Judkins, D., Brick, J. M., Broene, P., Ferraro, D., \& Strickler, T. (2000). NSAF Methodology Report No. 2. 1999 NSAF sample design. Retrieved February 10, 2005, from the Urban Institute Web site: http://www.urban.org/ Uploaded PDF/1999_Methodology_2.pdf

Kilpatrick, D. G., Resnick, H. S., Freedy, J. R., Pelcovitz, D., Resick, P. A., Roth, S., et al. (1998). Posttraumatic stress disorder field trial: Evaluation of the PTSD construct-Criteria A through E. In T. A. Widiger, A. J. Frances, H. A. Pincus, R. Ross, M. B. First, W. Davis, \& M. Kline (Eds.), DSM-IV sourcebook (4th ed., pp. 803844). Washington, DC: American Psychiatric Press.

Kilpatrick, D. G., Saunders, B. E., \& Smith, D. W. (2001). Research in brief: Prevalence and consequences of child victimization: Results from the National Survey of Adolescents. Washington, DC: National Institute of Justice.

Leavitt, L. A. (2002). When terrible things happen: A parent's guide to talking with their children. Journal of Pediatrics Health Care 16(5), 272-274.

March, J. S., Amaya-Jackson, L., Terry, R., \& Costanzo, P. (1997). Posttraumatic symptomatology in children and adolescents after an industrial fire. Journal of the American Academy of Child and Adolescent Psychiatry, 36, 1080-1088.

McFarlane, A. C., Policansky, S., \& Irwin, C. (1987). A longitudinal study of the psychological morbidity in children due to a natural disaster. Psychological Medicine, 17, 727-738.

Melnky, B. M., Feinstein, N. F., Tuttle, J., Modenhauer, Z., Herendeen, P., Veenema, T. G., et al. (2002). Mental health worries, communication, and needs in the year of the U. S. terrorist attack: National KySS survey findings. Journal of Pediatrics Health Care 16(5), 222-234.

Najarian, L. M., Goenjian, A. K., Pelcovitz, D., Mandel, F., \& Najarian, B. (1996). Relocation after a disaster: Posttraumatic stress disorder in Armenia after the earthquake. Journal of the American Academy of Child and Adolescent Psychiatry, 35, 374-383.

Najman, J. M., Williams, G. M., Nikles, J., Spence, S., Bor, W., Callaghan, M. O., et al. (2001). Bias influencing maternal reports of child behaviour and emotional state. Social Psychiatry and Psychiatric Epidemiology, 36, 186-194.

Offord, D. R., Boyle, M. H., Szatmari, P., Rae-Grant, N. I., Links, P. S., Cadman, D. T., et al. (1987). Ontario Child Health Study: II. Six-month prevalence of disorder and rates of service utilization. Archives of General Psychiatry, 44, 831-836.

Pfefferbaum, B., \& Pfefferbaum, R. L. (1998). Contagion in stress: An infectious disease model for posttraumatic stress in children. Child and Adolescent Psychiatric Clinics of North America, 7(1), 183-194.

Pynoos, R. S., Frederick, C., Nader, K., Arroyo, W., Steinberg, A., Eth, S., et al. (1987). Life threat and posttraumatic stress in school-age children. Archives of General Psychiatry, 44, 1057-1063.

Resnick, H. S., Kilpatrick, D. G., Dansky, B. S., Saunders, B. E., \& Best, C. L. (1993). Prevalence of civilian trauma and posttraumatic stress disorder in a representative national sample of women. Journal of Consulting and Clinical Psychology, 61, 984-991.

Schlenger, W. E., Caddell, J. M., Ebert, B. K., Jordan, K. M., Rourke, D., Wilson, L., et al. (2002). Psychological reactions to terrorist attacks: Findings from a national study of Americans' reactions to September 11. Journal of the American Medical Association 288, 581-598.

Schuster, M. A., Stein, B. D., Jaycox, L., Collins, R. L., Marshall, G. N., Elliott, M. N., et al. (2001). A national survey of stress reactions after the September 11, 2001, terrorist attacks. New England Journal of Medicine, 345, 1507-1512.

Shaw, J. A., Applegate, B., \& Schorr, C. (1996). Twentyone-month follow-up study of school-age children exposed to Hurricane Andrew. Journal of the American Academy of Child and Adolescent Psychiatry, 35, 359364.

Shaw, J. A., Applegate, B., Tanner, S., Perez, D., Rothe, E., Campo-Bowen, A. E., \& Lahey, B. L. (1995). Psychological effects of Hurricane Andrew on an elementary school population. Journal of the American Academy of Child and Adolescent Psychiatry, 34, 1185-1192.

Stuber, J., Fairbrother, G., Galea, S., Pfefferbaum, B., Wilson-Genderson, M., \& Vlahov, D. (2002). Determinants of counseling for children in Manhattan after the September 11 attacks. Psychiatric Services 53, 815-822.

Yule, W., Bolton, D., Udwin, O., Boyle, S., O'Ryan, D., \& Nurrish, J. (2000). The long-term psychological effects of a disaster experienced in adolescence: I. The incidence and course of PTSD. Journal of Child Psychology and Psychiatry and Allied Disciplines, 41, 503-511.

Received February 21, 2003

Revision received July 16, 2003

Accepted October 7, 2003 